\title{
THE CONTROL OF HIGH POTENTIAL SYSTEMS OF LARGE POWER.
}

BY E. W. RICE, JR.

The enormous increase in the use of electricity for lighting, traction and power has necessitated important changes in our generating stations. As the areas to be served have rapidly increased, corresponding increases have been made in the size of these stations and in the electrical potentials employed. The change has been due, not only to the great natural growth but to the consolidation of generating machinery into fewer stations. Instead of a number of separate stations, containing relatively small units producing electricity at comparatively low voltage with relatively large transmission losses, we now frequently find one large central station, containing generating units of great size delivering electricity at a high potential. Dynamos of 2,000 to 5,000 kilowatts capacity are displacing those of 200 to 500 kilowatts, and pressures of 5,000 to 15,000 volts those of 1,000 to 2,000 volts. The design and manufacture of large generating units of this character have called for engineering skill of a high order, and it can now be fairly claimed that the production of such machines has been reduced to an exact science.

The rapid evolution and present perfection in dynamo design have been due to the skill with which the various problems have been solved by the designing engineers and to the ease with which the data based upon machines of relatively small size were applied to those of larger size. 
It is evident, however, that great advances in the capacity and voltage of generators would be useless, if not positively dangerous, unless adequate means for controlling and switching the electrical current were at hand. The evolution of the dynamo was for a time more rapid than that of the devices for controlling and switching currents of large volume and potential. As a result, a number of machines of large size were placed in operation with comparatively inadequate methods of switching and controlling. The energy and power which can be safely concentrated in a single central station is obviously limited by the amount of current and voltage which switching devices can safely handle. This fact was especially forced upon the attention of the writer at the time when the company with which he is connected took the contract for the equipment of the generating station of the Metropolitan Traction Company of New York. This station was to contain eleven threephase dynamos, each of 3,500 kilowatts output at 6,600 volts. In order to realize the full economy of such a station, it was, of course, necessary that all the generators should supply current to a common bus bar, and that from these bus bars the current should be distributed throngh feeders to a number of substations. The sub-stations were to contain rotary converters, frequently working in multiple with large storage batteries on the direct current side. The eharacteristics of such a load prevented any reliance being placed upon the opening of the exciting circuit of the generators in case of the necessity of a general shut-down, as the rotary converters would, under certain conditions, supply sufficient magnetizing current to excite the generators, even with the field windings of the generators unexcited. It became, therefore, essential to produce a switching mechanism which would enable the generators to be connected and disconnected from the bus-bars with certainty and safety under all conditions of load, even up to a short-circuit, and also that the various feeders supplying the sub-stations should be capable of the same treatment. Three types of switching devices were available for this work and were carefully considered :

1. Switches breaking the circuit in the open air.

3. Switches arranged to break the circuit in an enclosed air space.

3. Switches arranged to break the circuit under oil. 
Switches of the first type (open air) were impracticable, because the space demanded to make such switches operative could not be provided.

Switches of the second type (enclosed air) had no such limitation, but oil-break switches were found to meet the conditions more perfectly. Tests conducted showed that energy up to 2,000 or 3,000 kilowatts could be controlled in a single oil switch at potentials as high as 15,000 volts, which was the limit of the apparatus at our disposal at the time. Switches of this type, however, as large as was considered necessary, required an amount of oil per switch so great as to be objectionable, in view of the large number of switches required for generators and feeders. The problem then was to produce a switch which would retain all the advantages of the usuai oil switch and at the same time minimize the quantity of oil.

The type which was finally evolved and employed in the Metropolitan installation has shown itself in practice to be remarkably successful. It is known as the Form " $\mathrm{H}$ " Oil Switch by the manufacturers, and was designed by the writer, with the assistance of Mr. E. M. Hewlett. It was described by Mr. J. E. Woodbridge in the Electrical World and Engineer of April 14th, 1900. Reference to this article will give the details, which I need not here repeat; I shall simply outline the principal features.

The switch, as designed for three-phase circuits, consists of three double-pole, single-phase switches, or elements. Each single-phase switch is contained in a fireproof cell, but all three switches are designed to be operated simultaneously. Each single-phase element consists of two brass cylinders or cans, one can for each pole. The in coming lead is attached to one of the cans and the out-going lead of the same phase to the other. Each cylinder is nearly filled with oil and is covered by a metal cap which carries a long insulating sleeve. Two copper rods joined by a metallic cross-head and forming together a U-shaped conductor, slide through the insulating sleeve and fit into tubular contacts at the bottom of the cans when closing the circuit. The cross-head of each U-shaped conductor is attached to a wooden rod, which extends through the top of the cell or casing which encloses the switch, and is in turn attached to a metal cross-head operated by an air motor or an electric motor, as the case may be. The three phases are seen, therefore, to be broken or closed simultaneously. When the three sets of U-shaped 


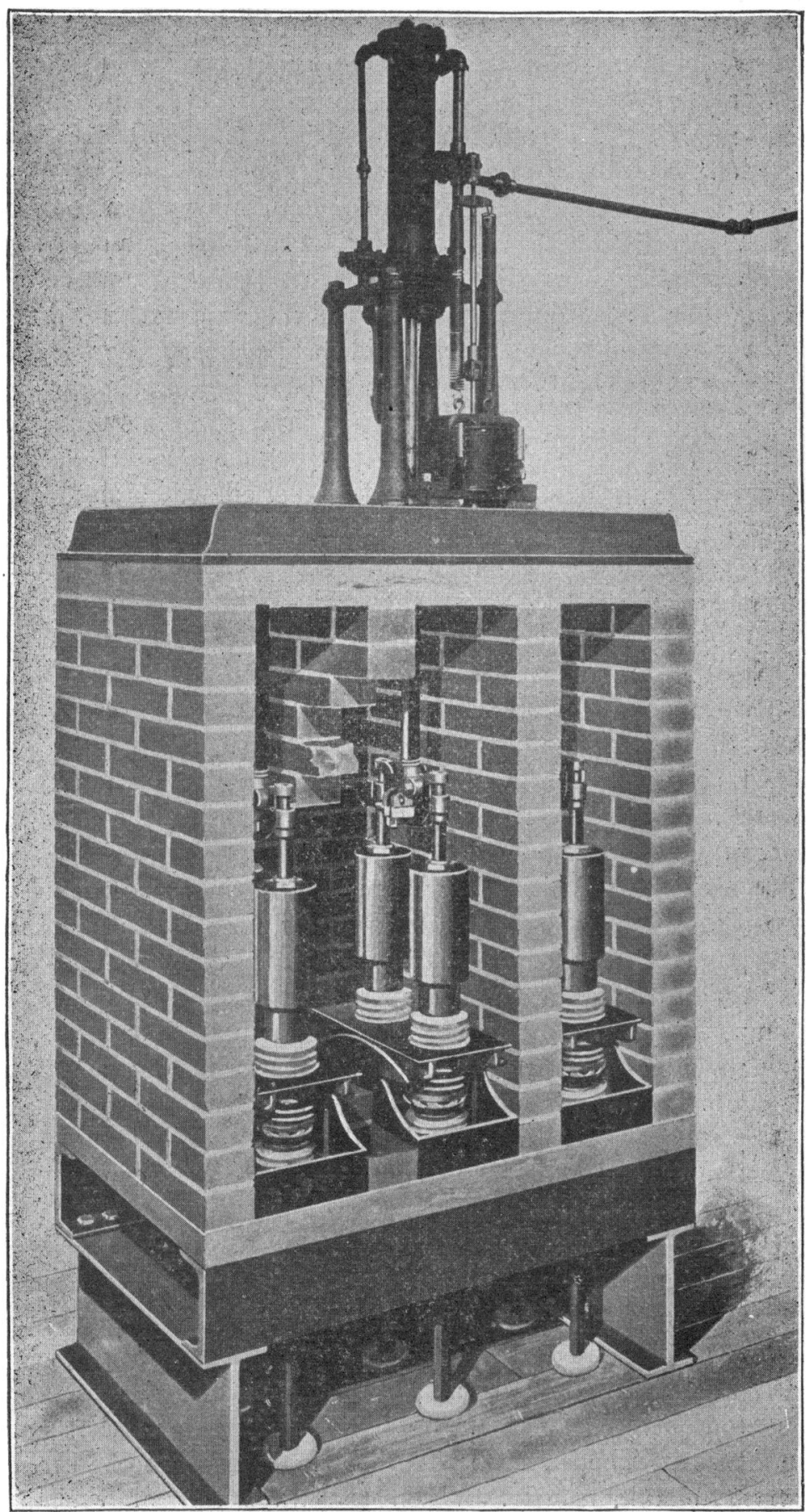

Fig. 1,-Pneumatically Operated Type H Switch, Metropolitan Traction Company's Station. 
conductors are lifted, the circuit is broken under the oil at two points in each phase, or six points in each complete three-phase switch. The range of movement of the cross-head varies with

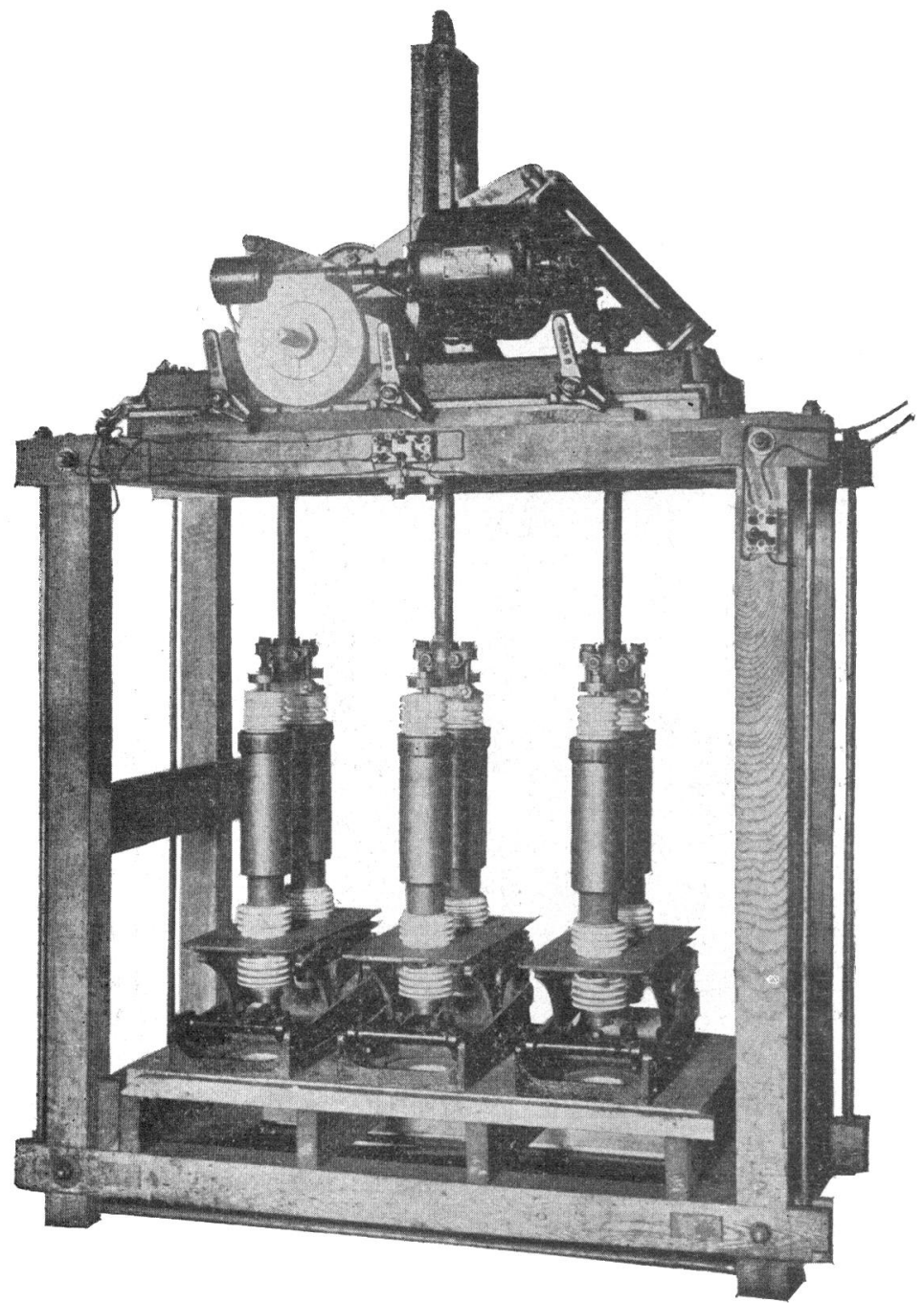

Fig. 2.-Electrically Operated Type H Switen for the Manhattan Railway Company, with brick partition removed.

the potential to be controlled, e. g., it is 12 inches in the switches in the Metropolitan station for 6000 volts, and 17 inches in the switches for the Manhattan station for 12,000 volts. The brass 
cans are lined internally with fiber to prevent the arc from jumping from the rod to the metal of the can when it is drawn up through the oil. Each switch unit stands alone on its own foundation, with the three phases in three separate cells or spaces separated by brick walls. These brick partitions act as barriers and prevent any possible burn-out in one cell from

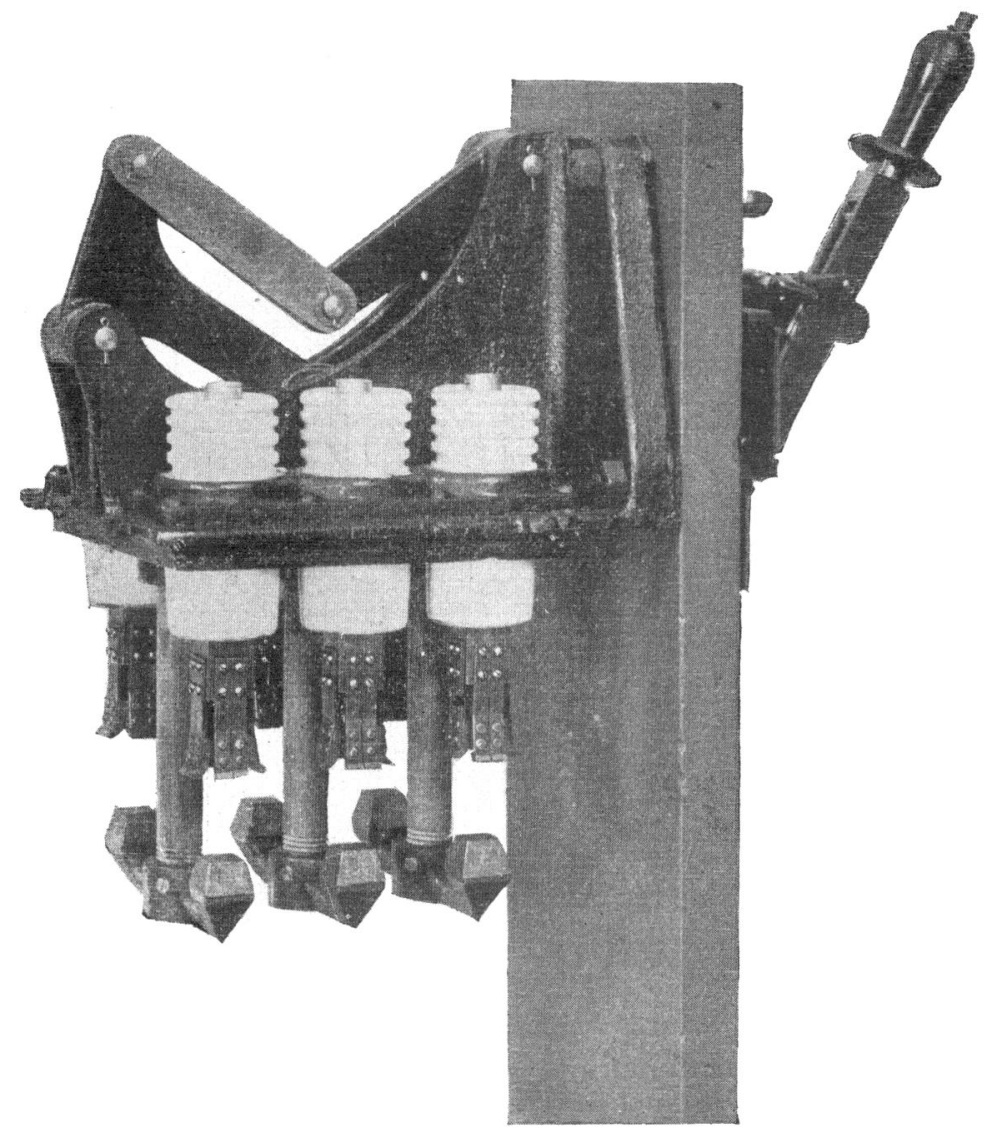

Fig. 3.-Form FK Oil Break Switch.

spreading to the others. As an opening of two legs breaks a three-phase line, an are in one cell will not incapacitate the switch. The circuit breaker or switch differs radically from older forms in the separation of the phases as indicated, and also in the separation of the contacts for each phase, in two separate oil pots. This separation of the terminals of each phase gives two separate ares, each enclosed in a space well removed from 
the others, so that the possibility of an are communicating from one pole to another is obviated. It will be seen that in breaking a three-phase circuit, the are is produced in six independent oil pots. This method of construction, together with the separation of the phases in separate fireproof compartments, accounts for the unusual effectiveness of the switch in practical operation. The general construction of the switch is clearly shown in the accompanying illustration.

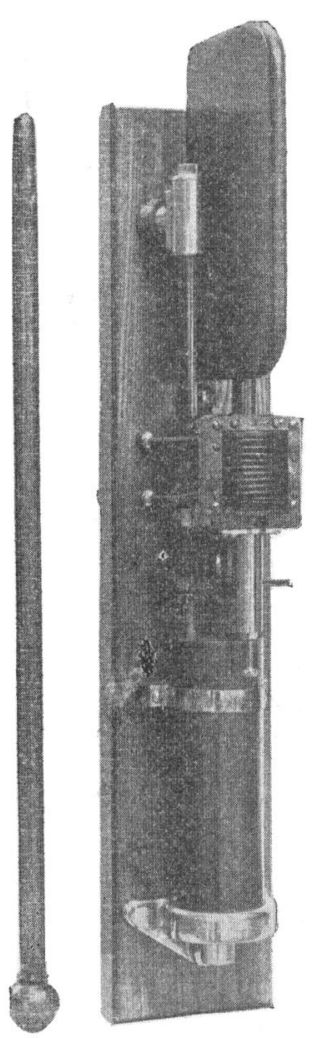

Fra. 4.-Expulsion type switch.

Fig. 1 shows the switch used in the installation of the Motropolitan Traction Co., New York. It is designed for 6600 volts and 300 to 800 amperes.

Fig. 2 shows the same switch as modified to suit the conditions of the Manhattan electric installation. On account of the higher voltage the oil pots are larger and a larger opening of the circuit is provided. The twelve covers for the oil pots are replaced by porcelain. It is designed for 12,000 volts and 300,800 amperes.

Fig. 3 illustrates the enclosed air tube type of switch already mentioned. This switch has given most excellent results on high potential work.

Fig. 4 shows the form FK, or tank oil switch, without tank for containing oil.

Fig. 5 is a reproduction from a photo taken at Kalamazoo of a special form of open air switch. The switch was opening a circuit of 25 ,000 volts and 60 amperes at the time when the photograph was taken.

It was at first thought that the use of oil switches for the control of high potential circuits would possibly result in resonance effects, particularly in circuits containing considerable capacity, such as underground cables or long overhead lines. A number of experiments have been conducted and the weight of evidence seems to be in favor of the oil switch as avoiding these 
effects. It has been found as an interesting fact that under the conditions described considerable disturbance due to resonance may occur upon the closing of a circuit. This is naturally independent of the character of the switch employed; it may

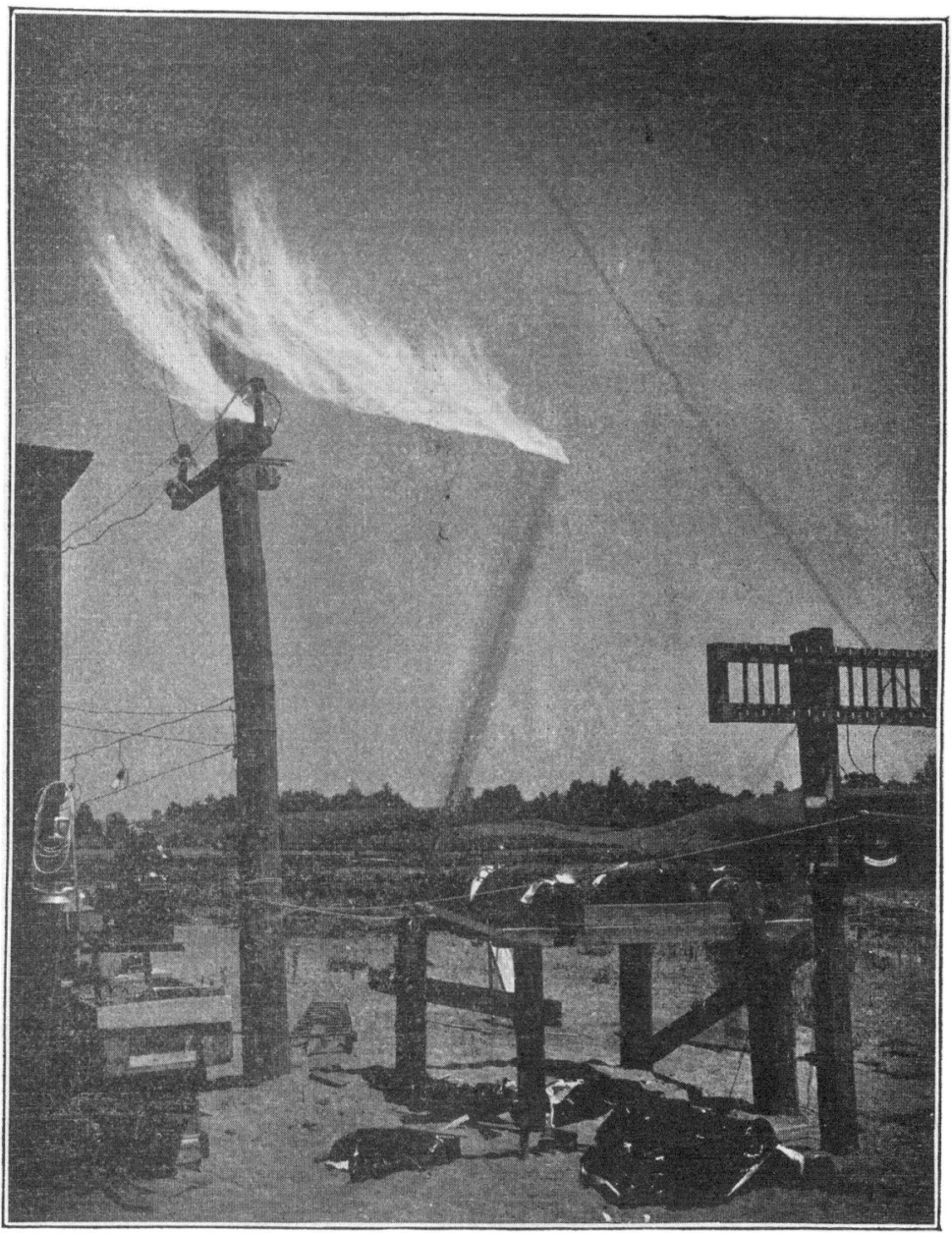

Fig. 5.-Air Break Switch (Kalamazoo Test).

vecur equally well with an oil, an enclosed air, or an open air switch.

Upon the rupture of the circuit, however, the results obtained from many tests indicate that open air switches are liable to produce heavy resonance effects while the enclosed air 
and the oil switch are practically free from such effects. Extensive experiments to determine this point were conducted prior to the production of the switches for the Metropolitan and Manbattan stations. Very recently experiments of a more severe character have been conducted at Kalamazoo, Mich. These tests were made at from 25,000 to 40,000 volts with from 1,200 to $1,300 \mathrm{~K}$. v. A. of highly inductive load, the power factor being from 40 to 60 per cent. The switches tested were the cylindrical oil switch, already described (Metropolitan type); an oil switch in which all the terminals were enclosed in a single tank of oil, called the tank oil switch, type " $\mathrm{K}$ "; a switch of the expulsion air tube type; and an open air switch in which the terminals were simply separated long distances in free air. In making these tests an oscillagraph was used to determine the time of break and other interesting effects, and a camera to photograph any particular instructive phenomena.

The long break open air switch, which operates upon the principle of drawing a long arc in the open air, opened the circuit at 25,000 volts, but required several seconds of time and drew such a long arc as to be impracticable. At 40,000 volts the arc held and flared to a total distance of over 30 feet until it struck the line and short-circuited the system, producing at the same time high-roltage oscillations equal to two or three times the normal potential of the system. It would therefore seem that the open air switch was generally unsuitable for the control of high-voltage systems of large powers, as even where sufficient room is available for their use, the production of higb resonance effects tends to endanger the system. These tests also show that wherever a short-circuiting are occurred in the open air, electric oscillations of high voltage resulted. These were probably due to the rapid alternate extinguishment and formation of the are during its period of interruption, the are acting somewhat in the manner of a Wehnelt interrupting device. The dangerous character of short-circuiting arcs emphasizes the need of the precautions which I shall mention in this paper; having in mind the avoidance, as far as possible, of such accidental shortcircuits.

The expulsion tube air switch operated up to 25,000 rolts, but failed at 40,000 .

The " $K$ " oil switch operated satisfactorily on 1,200 to 1,300 K. v. A. up to 25,000 volts, but at 40,000 volts it spat fire and 
occasionally emitted black smoke, thus seeming to be working at the limit of its capacity. Noattempt was made to open shortcircuits with the " $\mathrm{K}$ " switch.

The " $\mathrm{H}$ " oil switch never failed to open 1,200 to 1,300 K. v. A. at any voltage up to the maximum employed, 40,000 ; the circuit opening noiselessly and without the appearance of fire or emission of smoke at the switch. It was used as an emergency switch in all the tests to open short-circuits on 25,000 to 40,000 volts. The results of these and other tests, and the continued effective operation of the type " $\mathrm{H}$ " switch in the Metropolitan station indicate that this type of oil switch will safely control circuits of practically unlimited power at potentials considerably above 40,000 volts, probably as high as 100,000 volts.

The character of the break when operating properly was the same in all the switches except the open air type. In opening, the are held for a number of half-waves from $b^{2}$ to 18 and then broke at zero value without disturbance of the system. With the oil switches no traces of oscillation were noticed before the break, and no traces of rise of voltage. With the expulsion air switch, traces of oscillation were seen for a number of half-waves before the final break, and in consequence a slight voltage rise occurred.

I will not attempt to describe the numerous cbservations made at the Kalamazoo tests, as these will undoubtedly be given to you by our President, who supervised these tests and to whom I am indebted for the information which I have given regarding them.

In addition, however, to the production and use of a switch, which will be as safe and reliable as engineering skill can make it, there are certain other factors which should be considered in connection with the control of ourrent for high-potential stations which should be taken into consideration by the electrical engineer. It should be constantly kept in mind that no apparatus can be absolutely free from accident, no matter how carefully designs are constructed. The engineer should, therefore, carefully consider the possible effect of any accident, with particular reference to the possibility of an accident to one element involving other apparatus. The layout should be such that an accident to one element could not of itself, or in consequence of a chain of accidents, result in a breakdown of the entire generating station, even for a short time, 
The mechanical engineer has considered this point and met it with a fair degree of success in the large modern central station with the fire-proof boiler house and the frequent subdivision of this boiler house into two or more portions by suitable fire walls, as in the case of those of more than one story.

The general employment of a duplicate system of steam piping, or its equivalent, also provides a reasonable safeguard against failure of supply from accidental disarrangement of a steam system. The steam engines in well arranged stations, being important units, are placed a sufficient distance apart, and so disposed, generally, that an accident to one will not easily involve other units. This is also true of the dynamos which are directly coupled to the engines.

The switchboard with its switches for controlling and appliances for measuring the output of the generating station, the cables leading from the generator to the switchboard, the location of the bus-bars, and the disposition and arrangement of the feeder cables for distributing the current, have not as a rule been given that serious attention which their importance deserves. In fact, the consideration of the electrical controlling devices and the wiring of the station has been apparently left to the last, and it is frequently the case that a generating station containing apparatus of great value has been jeopardized by the lack of eareful design of the switching appliances. Stations designed to deliver a normal output of from 5,000 to 10,000 kilowatts, at relatively high pressures, say 5,000 volts or upwards, frequently contain switches for controlling the generators and the feeders mounted upon the face of a long continuous panel, and so crowded together that in case of failure to open the circuits the resulting are would be almost certain to involve adjacent switches and even possibly cripple the station for a time. The bus-bars are also often so disposed that an are may easily start thereat or at least so that an are, if started for any cause, would be liable to seriously darnage the switchboard.

The same methods frequently obtain in regard to the manner of installing the conductors; high tension and low tension conductors being often mixed together and the conductors so arranged that in case of an injury to one, other of the conductors leading from the generators or from the switchboard out of the station are in danger of being involved.

These methods have probably arisen from the fact that up to 
a comparatively recent period the service of a city for lighting and for power has been separated among a number of different stations, each of a relatively limited amount of power. In case of the failure of any individual unit in such case, as of the generator, switchboard, or other apparatus, the damage was small, owing to the limited energy available. A shut-down, even of the whole station, was comparatively unimportant. However, the case is quite different with the large modern station with output of from 10,000 to 100,000 horse-power, which is designed to supply electrical energy for a large portion of a city's needs, combining frequently electric power for traction purposes, electricity, for lighting. etc. The economies expected of such stations -lower cost of operation, smaller investment, and greater economy in coal and in steam-due to the better load-curve obtained by the concentration of loads of large area and of various character in one station, as well as to the higher efficiency of the large units, are familiar to all electrical engineers. I am inclined to think, however, that the possible dangers of such a concentration of energy have not been fully realized. The failure of such a station, even for a brief period, would be a disaster which, with proper design, need not occur.

I will briefly outline the principles which I believe should govern in the layout of such a central station, the details of which may naturally be varied considerably to suit local conditions. It should be kept in mind that I am discussing stations of normally large output, say 5,000 kilowatts and over, although many of the principles mentioned could probably be applied with advantage to stations of smaller size. Broadly speaking, I would carry the principle of subdivision into units as far as practicable; the units to be chosen with respect to the size of the station, character of luad-curve, etc. The builer house, as already stated, should be subdivided into two or more distinct portions, so that injury to one will not involve the entire steam system. Fortunately, the foundations, masonry and mounting of boilers are so essential and of such a nature that damage to one unit is not liable to involve another. At the same time, it is important that the boiler house should be divided into two or three sections, separated from each other by brick partitions. The steam piping should be in duplicate or a substantial equivalent, and so arranged that the bursting of a steam main cannot flood all the boiler rooms with steam or stop the entire flow of steam to the engine room. 
The engines, with the dynamos coupled thereto, may be placed in one large room, provided this room is of sufficient size to en: able the units to be placed at proper distances apart. The switchboard should preferably be placed in a separate room, so that any accident to the engine or to the steam piping will not injure the switchboard operator or the switchboard mechanism. The electrical conductors from each dynamo should be led to the switchboard as far apart as possible from those of other units. Each set of conductors should be led to its own switch. Each switch should be of ample capacity to interrupt the entire output of the generator at full voltage and even take care of the concentration of the entire load of the station, as in a shortcircuit. This switch should be placed in a cell of fireproof material and preferably electrically controlled from a central point. If so disposed, these switches may be placed reasonably close together, but the partitions should be such that any one of the switches could arc to destruction without involving the switch of a neighboring generator. Switches should be in duplicate, so that in case of failure of one, another switch will be in readiness. Especial care should be taken, in leading the conductors from the switches to the bus-bar, to keep the conductors as far as possible from those of neighboring units.

The bus-bar or bars should preferably be in duplicate, or some equivalent arrangement such as sectional subdivision should be adopted. Bus-bars should be carefully protected in fireproof compartments so arranged that it would be impossible for any arc to short-circuit from one conductor to another or for it to be injured by an are caused by the destruction of any of the generator or feeder switches. The same care should be taken to isolate the conductors leading from the bus-bars to the feeder switches. The feeder switches should also be in duplicate; that is, two separate sets of switches on each feeder in series with each other when feasible, or the conductors leading to a group of feeders may be joined together by a switch placed in series therewith controlling a group of feeders. Each group series and each of the feeder switches should be mounted in its own separate fireproof compartment and preferably controlled electromagnetically from a distance. The conductors leading from the feeders out of the station should not be massed together in one conducting trench or well, but should be subdivided into as many groups as circumstances will permit. 
The constant aim throughout the entire station should be to limit the normal flow of energy in a given space to a pre-determined amount, preferably for example, to that of the generator unit which has been selected, or in the case of the feeders leading outside the station the normal flow of a group may be limited. to that delivered to any one substation.

It is obvious that the arrangement of switchboard, as described, will occupy more space than the ordinary panel type. The total space occupied, however, is but a small portion of the total space required for the generating plant, and it is believed that the precautions recommended are essential to the continued success and reliability of large generating plants. Such separation of the switches, etc., makes some method of control from a distance very desirable. The motors used for operating the switches may be either pneumatic or electric. The control of these motors should preferably be electric in all cases. By adopting electric control from a distance, it is possible to combine all the switches required for the generator, feeders, etc., upon a small keyboard under the observation and control of a single operator. It is also possible to place this operator in such a position that he will have a comprehensive survey of ail the measuring and controlling devices needed for the station, and at the same time be free from danger in case any of the apparatus should fail to perform its work. Under such circumstances the operator is much less liable to make a mistake, and it is believed that having taken such precautions accidents even of a trivial character will be more unlikely to occur. In laying out the electrical devices for such a station the utmost simplicity should be aimed at; not a single instrument, conductor or switch being placed in the station that has not been carefully considered and felt to be essential. It is better to err on the side of simplicity than of complexity. 